底及时积水，使鍋底与鍋身在反应过程中情况相

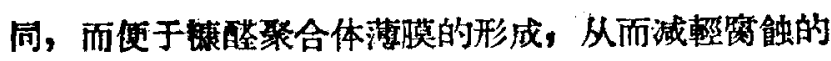
措施。

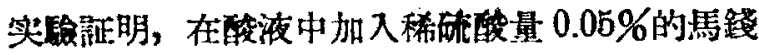

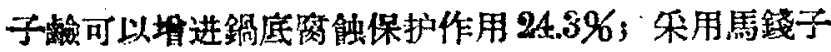

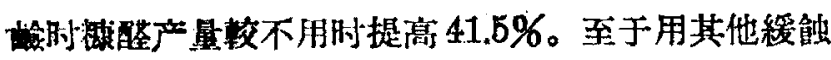

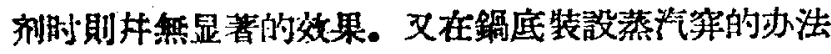

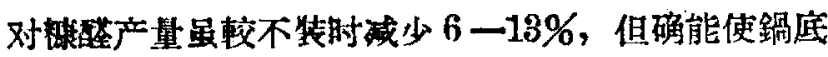

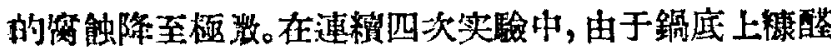
聚合体满膜的濑桷生成，其抗会能力乃逐步提高。以 第四次与第一次比较，“抗飭能力莞提高达80倍以上。

張 承 琦

(成都工学浣塑料工学称租) 1956年11月17日

\section{用紙上層析法判定糖發 酥鍳定醭母的試驗}

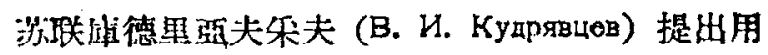

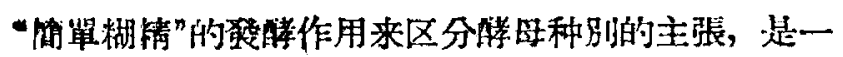
项值得重視的意見，因为这种方法簡便地將雨种醉

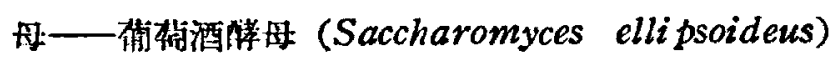
和叫酒腈母 (Saccharomyces cerevisiae) 一明显

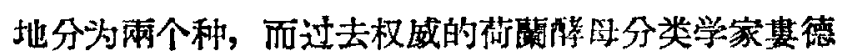

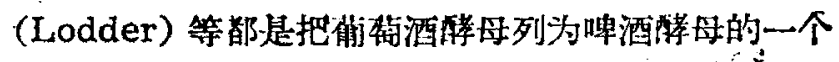

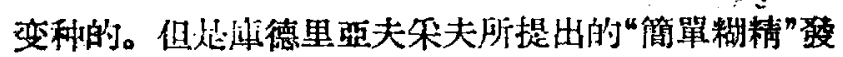

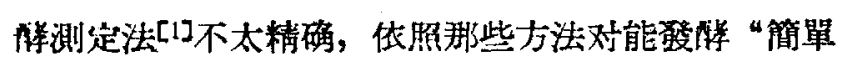

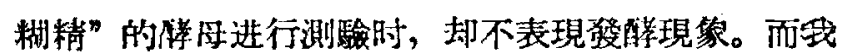

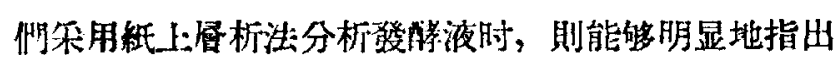

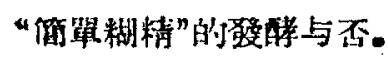

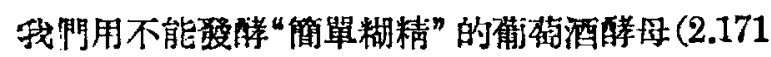

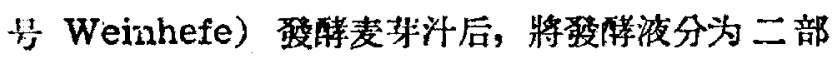
分: 一部分直接接种能㹲睹“简單糊精”的德国十二号

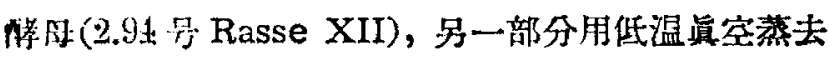
酒精后种入同一种腾时。發醭結果，均無 $\mathrm{CO}_{2}$ 生出， 可是用竝上展析測驗的結果，可以明白指出“简單糊

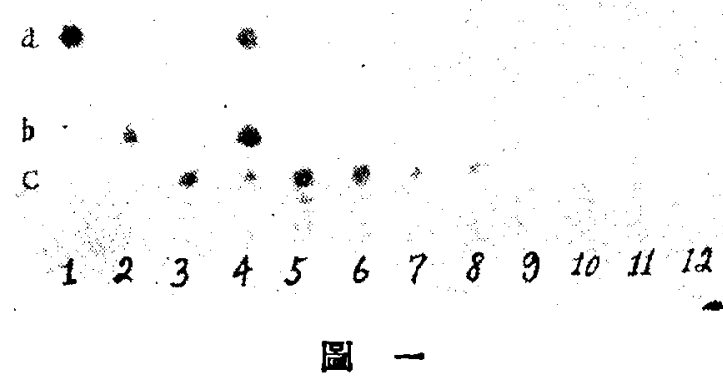

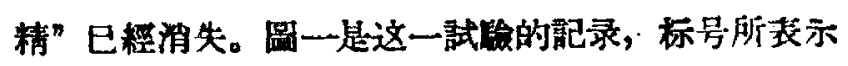

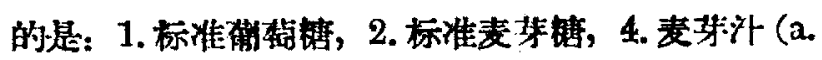

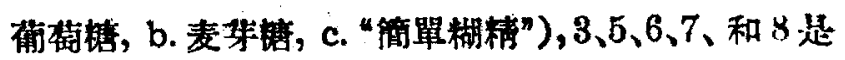
不能發情“简單糊精”的五种睹母 (2.171 Weinhefe, 28 Apple yeast, 2.29 charente fine champagne, 2.119 Sacch. formosensis, 2.133 Wein Ko-

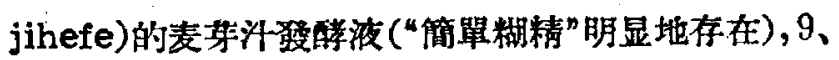

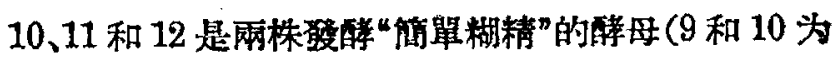

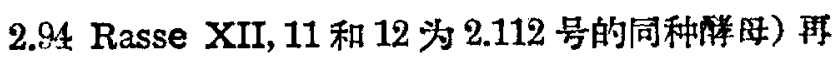

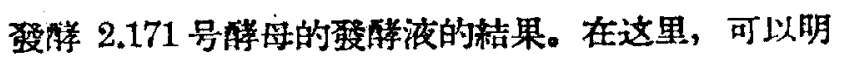
显地看出“简單糊精”已因醇而消失了。

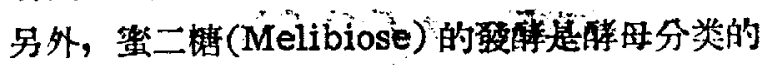
重要根据之一，可是因为价值娟贵，且不易买到，因 此，䐗母分类学家（如串德、庫德里亞夫朵夫等）都

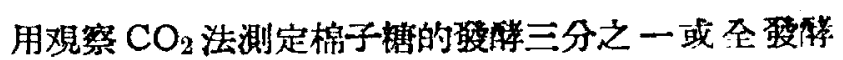

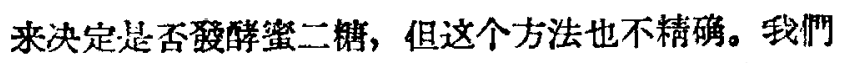

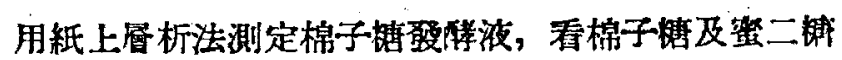

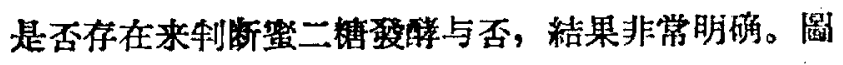
二是紙上畨析法的結果的照片, 标号代表的是: 1. 标

$$
\begin{gathered}
12345678910 \\
=
\end{gathered}
$$

准敏二榶，2.标准棉子棈，3. 加棉子榶的互身汭，4.

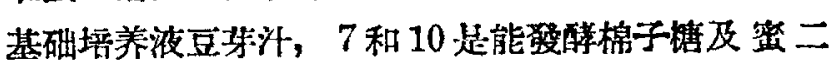
緯的雨种醉母 (2.53 号 Sacch. Logoh, 2.417 号Sacch.

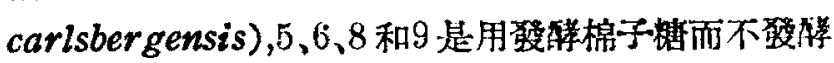

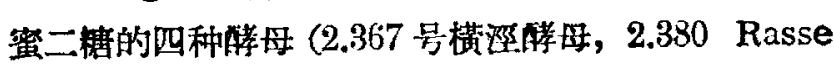
33,2.247 Schizos. asporus 及 2.94 号 Rasse XII)

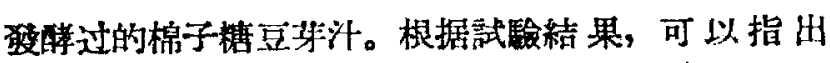
2.53 及 2.417 号睹母能够醉棉子榶及虽二榶，而其

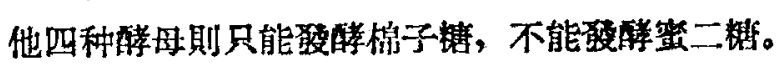

我們試验所用的是一般的紙上居析法，扩散剂是 丁醇醋酸水溶液，显色剂是数苯二甲醖苯胺。

\section{本明寝 方心芳 (中国科学院菌种保较委角会) 1956 年 12 月 7 日}

[1] В. И. Кудрявиев, Систематика Дрожжой, 125$126,1954$. 